\title{
ARTIGOS
}

\section{EDUCAÇÃO SEXUAL EM ESCOLAS BRASILEIRAS: REVISÃO SISTEMÁTICA DA LITERATURA}

MILENE FONTANA FURLANETTO'

FRANCIELE LAUERMANN"

CRISTOFER BATISTA DA COSTA"I

ANGELA HELENA MARINIV

\section{RESUMO}

No presente estudo, realizou-se uma revisão sistemática da literatura sobre educação sexual em escolas brasileiras, a fim de identificar suas principais características, temas abordados e profissionais responsáveis pelas ações. A pesquisa resultou em 24 artigos empíricos publicados entre 2010-2016, obtidos nas bases Educ@, Science Direct, MEDLINE, LILACS e SciELO. Constatou-se que as ações revisadas não atendem ao preconizado nos Parâmetros Curriculares Nacionais quanto à transversalização do tema. Destaca-se a necessidade de avançar no seu debate e investir em capacitação docente com vistas a transformar padrões sexuais discriminatórios e promover uma cultura de prevenção em saúde no ambiente escolar.

REVISÃO DE LITERATURA • EDUCAÇÃO SEXUAL • ESCOLA • SEXUALIDADE

Universidade do Vale do Rio dos Sinos (Unisinos) São Leopoldo (RS), Brasil; mileneff@gmail.com

Universidade do Vale do Rio dos Sinos (Unisinos), São Leopoldo (RS), Brasil; lavermannfranciele@ gmail.com

III

Universidade do Vale do Rio dos Sinos (Unisinos) São Leopoldo (RS), Brasil: cristoferbatistadacosta@ gmail.com
SEXUAL EDUCATION IN BRAZILIAN EDUCATION:

\section{SYSTEMATIC REVISION OF THE LITERATURE}

\section{ABSTRACT}

The present study conducted a systematic review of the literature on sexuality education in Brazilian schools, in order to identify its main characteristics, topics addressed and professionals involved. The research resulted in 24 empirical articles published between 2010-2016, obtained from Educ@, Science Direct, MEDLINE, LILACS and SciELO databases. It was determined that the actions reviewed do not meet the recommendations of the Parâmetros Curriculares Nacionais [National Curricular Parameters] regarding the mainstreaming of the theme. It is important to emphasize the need to extend this debate and to invest in teacher training with a view to transforming discriminatory sexual patterns and promoting a culture of prevention in health in the school environment. 


\section{ÉDUCATION SEXUELLE DANS LES ÉCOLES BRÉSILIENNES : RÉVISION SYSTÉMATIQUE DE LA LITTÉRATURE}

RÉSUMÉ

Cette étude a réalisé un examen systématique de la littérature sur l'éducation sexuelle dans les écoles brésiliennes, afin d'identifier ses principales caractéristiques, les thèmes abordés et les professionnels impliqués dans les actions. 24 articles empiriques publiés entre 2010 et 2016 ont été trouvés à partir des bases de données Educ@, Science Direct, MEDLINE, LILACS et SciELO. Il a été constaté que les actions étudiées ne répondent pas à ce qui est préconisé dans les Parâmetros Curriculares Nacionais [Paramètres des Programmes Nationaux] concernant la transversalisation du thème. Cela met en avant la nécessité d'approfondir le débat, d'investir dans la formation des enseignants pour transformer les comportements discriminatoires en termes de sexualité et de promouvoir une culture de prévention de la santé en milieu scolaire.

REVUE DE LITTÉRATURE • ÉDUCATION SEXUELLE • ÉCOLES • SEXUALITÉ

\section{EDUCACIÓN SEXUAL EN ESCUELAS BRASILEÑAS:} REVISIÓN SISTEMÁTICA DE LA LITERATURA

RESUMEN

En el presente estudio, se realizó una revisión sistemática de la literatura sobre educación sexual en escuelas brasileñas, a fin de identificar sus principales características, temas abordados y profesionales responsables por las acciones. La investigación produjo 24 artículos empíricos publicados entre 2010-2016, obtenidos en las bases Educ @, Science Direct, MEDLINE, LILACS y SciELO. Se constató que las acciones revisadas no atienden a lo preconizado en los Parâmetros Curriculares Nacionais [Parámetros curriculares nacionales] sobre la transversalidad del tema. Se destaca la necesidad de avanzar en su debate e invertir en capacitación docente con miras a transformar patrones sexuales discriminatorios y promover una cultura de prevención de la salud en el ambiente escolar. 

do desenvolvimento dos sujeitos, influenciado por aprendizagens e experiências sociais e culturais (LOURO, 2008), que remete ao prazer e à qualidade de vida. Inicialmente, o processo de educação sexual ${ }^{1}$ ocorre, informalmente, a partir das relações com o ambiente, tendo a família como referência, e, formalmente, como prática pedagógica, nas escolas e instituições sociais (FIGUEIRÓ, 2010; FURLANI, 2011a).

O desenvolvimento das práticas de educação sexual nas escolas começou no início do século XX, tendo como foco o controle epidemiológico. Na época, prevaleciam discursos que eram, em geral, repressivos, ancorados nos pressupostos da moral religiosa e reforçados pelo caráter higiênico das estratégias de saúde pública (FIGUEIRÓ, 2010; SFAIR; BITTAR; LOPES, 2015). Com o avanço das discussões políticas a respeito dos direitos sexuais e reprodutivos, em que o movimento feminista teve forte participação, ampliaram-se as discussões acerca da sexualidade para além do caráter biológico, possibilitando que fosse compreendida como prática aliada à saúde física e mental (SFAIR; BITTAR; LOPES, 2015; TAQUETTE, 2013).

Dentre as contribuições políticas que abordaram a temática, destacam-se os documentos produzidos a partir de conferências realizadas no Cairo e Pequim, na década de 1990, que atentaram para temas como direitos humanos, liberdade sexual, saúde e educação. Enfatizou-se a responsabilidade dos Estados em facilitar o acesso às informações 
relativas à saúde sexual e reprodutiva por meio de políticas públicas e desenvolver ações que abrangessem temáticas de planejamento familiar, métodos contraceptivos, aborto seguro (conforme a permissão do país), aconselhamento e serviços obstétricos (MORAES; VITALLE, 2015; TAQUETTE, 2013). Tais mudanças também impactaram a educação de crianças e adolescentes. Reconheceu-se que a sexualidade é constitutiva dos sujeitos desde a infância e, portanto, a escola foi considerada local privilegiado para políticas e projetos que garantam os direitos reprodutivos e sexuais de seus alunos no âmbito da educação (GAVA; VILLELA, 2016; GESSER; OLTRAMARI; PANISSON, 2015).

Em consonância ao exposto, em 1996, foi aprovada a terceira e mais recente Lei de Diretrizes e Bases da Educação Nacional (LDB), que deu origem aos Parâmetros Curriculares Nacionais (PCN) (BRASIL, 1998), publicados em 1998, cujo objetivo era orientar as escolas na reformulação de propostas pedagógicas, visando à melhoria das práticas e à coerência dos investimentos no sistema educacional brasileiro. Dentre os dez cadernos nos quais os PCN se organizam, há um de orientação sexual, que visa a abordar o tema da sexualidade no ambiente escolar. Segundo o documento, o objetivo da orientação sexual ${ }^{2}$ é contribuir para que os alunos possam desenvolver e exercer sua sexualidade com prazer, saúde e responsabilidade. Propõe-se que seja trabalhado transversalmente, perpassando todas as disciplinas, em consonância com uma visão ampla de sexualidade, incluindo seu caráter cultural, social e histórico (BRASIL, 1998; PALMA et al., 2015).

Aproximadamente vinte anos após a publicação dessas orientações, questionam-se a realização e efetividade de práticas voltadas à sexualidade, uma vez que pesquisas sobre comportamentos sexuais de adolescentes evidenciam que esse público tem colocado sua saúde em risCO (ESPADA; MORALES; ORGILÉS, 2014; GONZÁLEZ et al., 2010; OLIVEIRA; BÉRIA; SCHERMANN, 2014). Por exemplo, estima-se que a iniciação sexual precoce, com idade aproximada aos 15 anos, está associada ao menor uso de preservativo, aumento da frequência de relações sexuais, número de parceiros e, consequentemente, à maior vulnerabilidade às doenças sexualmente transmissíveis e gestações não planejadas (ESPADA; MORALES; ORGILÉS, 2014; GONZÁLEZ et al., 2010; TEIXEIRA et al., 2006).

Além disso, discute-se a conduta discriminatória de professores e demais profissionais da escola frente às manifestações sexuais dos alunos (GESSER; OLTRAMARI; PANISSON, 2015; NARDI; QUARTIERO, 2012; MADUREIRA; BRANCO, 2015). Tal fato pode estar associado à evidência de que grande parte dos professores não tem recebido capacitação para lidar com temáticas relacionadas à sexualidade, o que reforça a propagação de propostas pedagógicas amparadas em concepções religiosas, higienistas e heteronormativas (GESSER; OLTRAMARI; PANISSON, 2015; 2 MADUREIRA; BRANCO, 2015). 
No campo político, desde 2004, com o surgimento do movimento "Escola sem Partido", aproximadamente 60 projetos de lei tramitaram ou tramitam no Congresso Nacional e casas legislativas objetivando impedir a doutrinação política e ideológica de alunos por parte de professores nas escolas. Dentre as solicitações, encontra-se a exclusão dos termos orientação sexual e gênero do Plano Nacional da Educação (PNE) e Base Nacional Comum Curricular (BNCC) (BRASIL, 2017), esta última homologada em 22 de dezembro de 2017. Tal atitude tem sido repudiada pelo Conselho Nacional dos Direitos Humanos (CNDH) por meio da resolução n. 7/2017, da Lei n. 13.005/2014 (BRASIL, 2014) e dos Projetos de Lei n. 7180/2014 (SANTANA, 2014) e n. 867/2015 (FERREIRA, 2015).

Em 2015, a Pesquisa Nacional da Saúde do Escolar (PeNSE), realizada em parceria com o Ministério da Saúde, Ministério do Planejamento, Desenvolvimento e Gestão e o Instituto Brasileiro de Geografia e Estatística (IBGE), coletou informações a respeito do desenvolvimento, saúde e educação de 102.072 adolescentes escolares brasileiros pertencentes ao $9^{\circ}$ ano do ensino fundamental. Os resultados apontaram que 87,3\% relataram ter recebido informações sobre doenças sexualmente transmissíveis (DST) e HIV/AIDS na escola (IBGE, 2016). Tais dados corroboram outros estudos que indicam que aproximadamente $70 \%$ dos estudantes adolescentes referem receber algum tipo de informação ou prática aliada à saúde sexual (GONDIM et al., 2015; OLIVEIRA; BÉRIA; SCHERMANN, 2014; SILVA et al., 2015). No entanto, essas pesquisas não referem de que forma a educação sexual vem ocorrendo nas escolas, o que impossibilita identificar sua congruência com o que é orientado pelos PCN.

Considerando os desafios relacionados à implantação dos PCN (GONDIM et al., 2015; OLIVEIRA; BÉRIA; SCHERMANN, 2014; SILVA et al., 2015) e reconhecendo a educação sexual como instrumento de transformação social capaz de contribuir para mudanças de comportamento e de normas relacionadas à sexualidade, mostra-se relevante e oportuno analisar de que forma ela vem sendo trabalhada nas escolas (FIGUEIRÓ, 2010). Desse modo, este estudo tem como objetivo realizar uma revisão sistemática da literatura sobre a educação sexual em escolas brasileiras, a fim de identificar suas principais características (ano de publicação, autoria, título, objetivos e delineamento), assim como os temas abordados e os profissionais responsáveis pelas ações.

\section{MÉTODO}

O presente estudo é uma revisão sistemática da literatura desenvolvida de acordo com as diretrizes do Preferred Reporting Items for Systematic Reviews and Meta-Analyses (PRISMA). O processo de busca bibliográfica foi realizado de julho a outubro de 2016 nas seguintes bases de dados: 
Educ@, Science Direct, MEDLINE, LILACS e SciELO. Os critérios utilizados para a escolha dessas bases foi serem de domínio nacional e incluirem artigos relacionados às ciências da saúde e educação. Os descritores e operadores booleanos utilizados para pesquisa foram: 1) "educação sexual” AND escola, 2) “orientação sexual” AND escola e 3) sexualidade AND educação.

O procedimento inicial de busca dos estudos foi realizado pela primeira autora. Inicialmente, foram excluídos os artigos duplicados e que não estavam disponíveis para acesso na íntegra, bem como as pesquisas internacionais. Após, procedeu-se à leitura dos resumos, analisando se constavam de informações sobre ações relativas à sexualidade na escola. Na etapa seguinte, os artigos selecionados foram lidos na íntegra por duas das autoras para avaliação da elegibilidade dos estudos (índice de concordância de 84\%). Os critérios de inclusão definidos para a triagem dos artigos foram: estudos nacionais empíricos sobre educação/ orientação sexual nas escolas, publicados entre o período de 2010-2016, nos idiomas português, inglês e espanhol. Foram excluídos artigos que buscavam compreender a percepção dos professores sobre sexualidade, artigos que relatavam estratégias de educação/orientação sexual fora do ambiente escolar e artigos sobre educação sexual na família, uma vez que não eram o foco do presente estudo.

A Figura 1 representa o fluxograma de identificação e seleção dos artigos localizados. A busca nas bases de dados resultou na identificação inicial de 586 artigos. Após a primeira etapa de seleção, foram eliminados 295 estudos. A partir da leitura dos resumos, foram excluídos mais 190 artigos, os quais não se referiam à educação/orientação sexual em ambiente escolar. Os 101 artigos remanescentes foram analisados na íntegra, considerando os critérios de inclusão e exclusão, restando 24 artigos para avaliação final. 


\section{FLUXOGRAMA DE SELEÇÃO DOS ESTUDOS (PRISMA)}

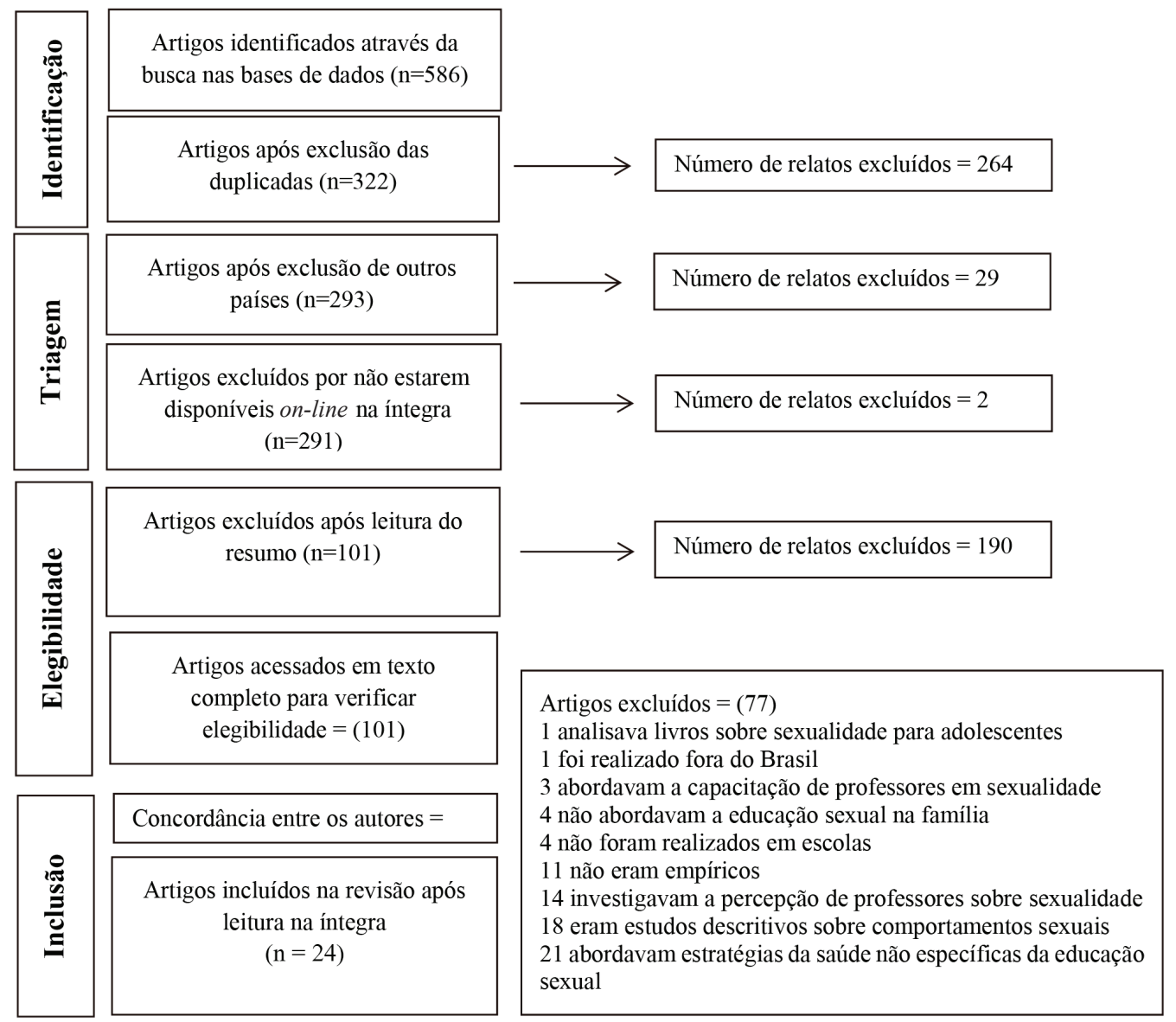

Fonte: Elaboração dos autores.

Os dados foram submetidos à análise temática, conforme proposto por Braun e Clarke (2006). Os artigos selecionados foram lidos diversas vezes até que se obtivesse familiarização com os dados para identificar os temas de análise, considerando os objetivos do estudo, como será apresentado a seguir.

\section{RESULTADOS}

Com vistas a identificar as principais características das ações de educação sexual realizadas em escolas brasileiras, o Quadro 1 apresenta os estudos selecionados, indicando o ano de publicação, autoria, título do estudo, objetivos e delineamento. Quanto à temática das ações em educação sexual nas escolas, emergiram dois temas para análise: a) características da educação sexual nas escolas, do qual derivaram três categorias: objetivo das ações de educação sexual, características metodológicas-pedagógicas e temáticas abordadas nas intervenções; além de b) profissionais que desenvolvem as ações de educação sexual nas escolas. 


\begin{tabular}{|c|c|c|c|c|c|c|c|c|c|c|c|}
\hline 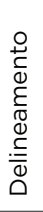 & 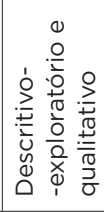 & 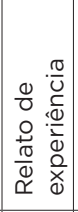 & 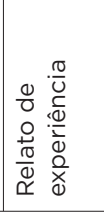 & 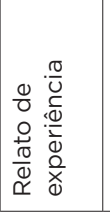 & 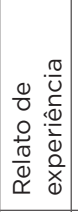 & 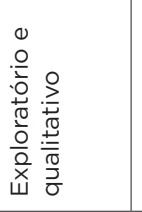 & 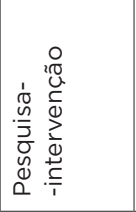 & $\begin{array}{l}0 \\
0 \\
0 \\
0 \\
0 \\
0 \\
0 \\
\bar{y} \\
\overline{0} \\
0 \\
0 \\
0\end{array}$ & 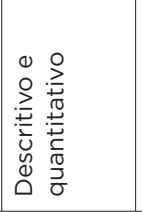 & 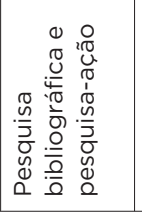 & 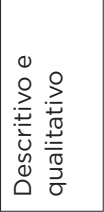 \\
\hline 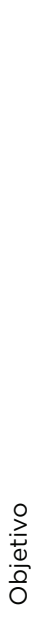 & 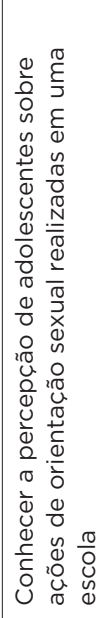 & 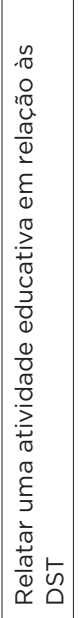 & 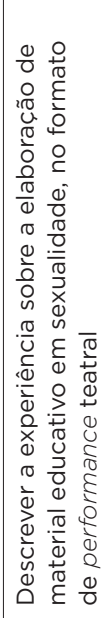 & 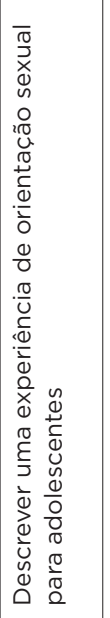 & 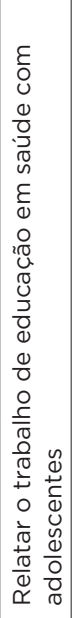 & 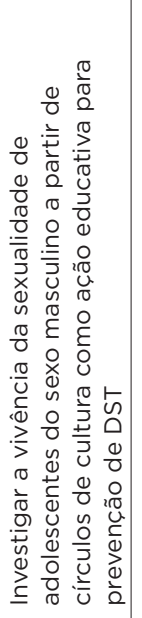 & 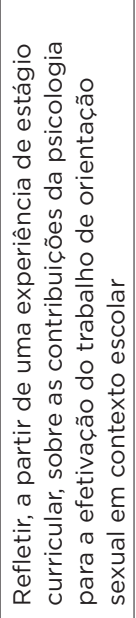 & 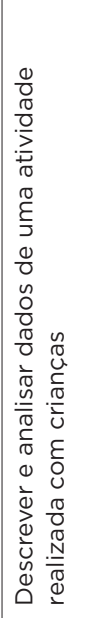 & 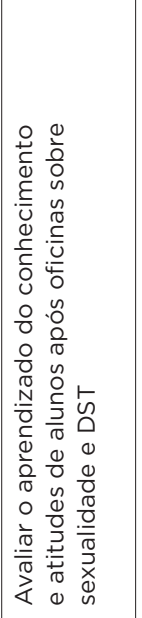 & 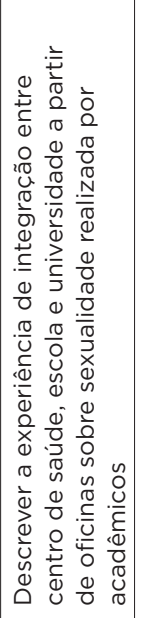 & 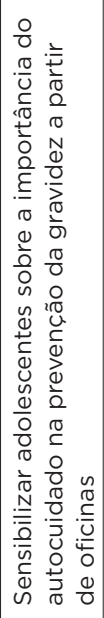 \\
\hline$\stackrel{0}{\frac{0}{3}}$ & 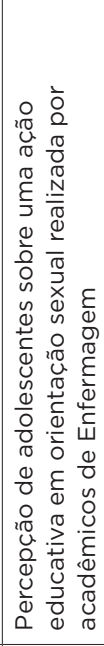 & 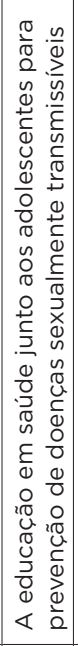 & 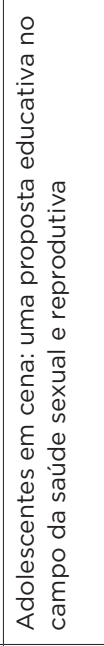 & 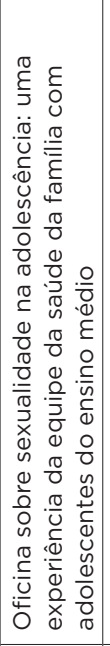 & 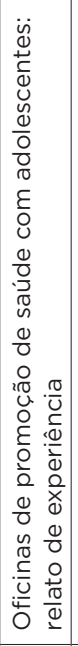 & 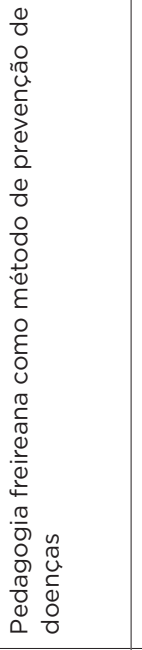 & 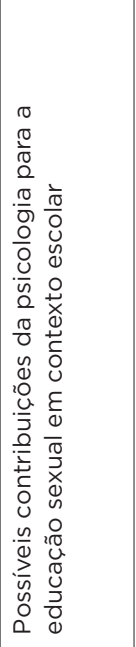 & 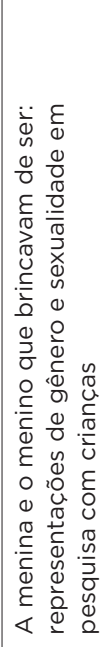 & 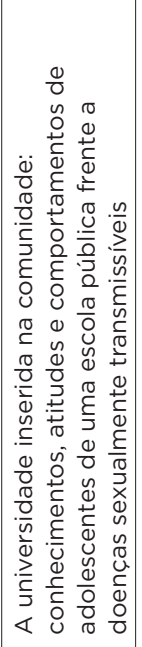 & 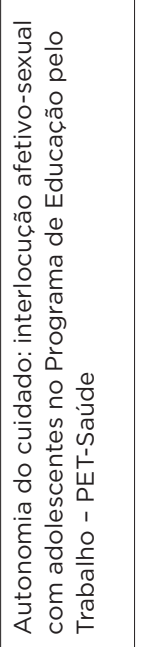 & 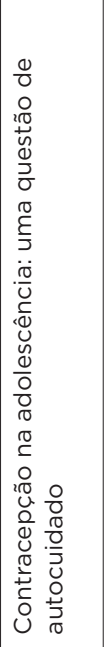 \\
\hline 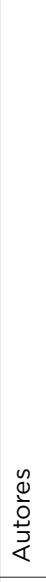 & 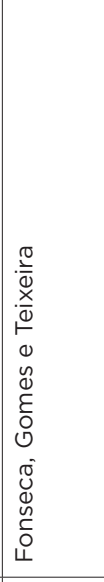 & 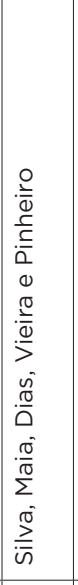 & $\begin{array}{l}0 \\
N \\
0 \\
0 \\
\text { in }\end{array}$ & 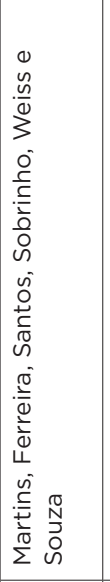 & 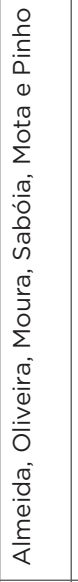 & 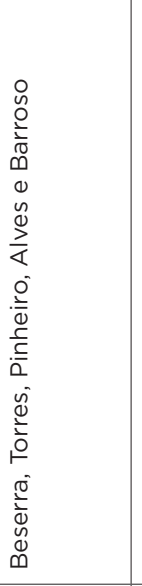 & 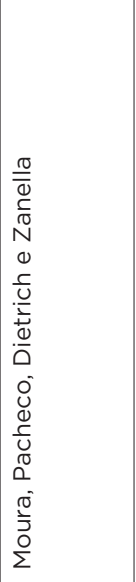 & 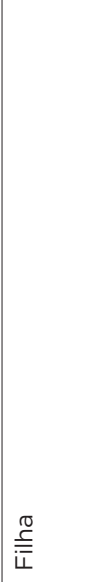 & 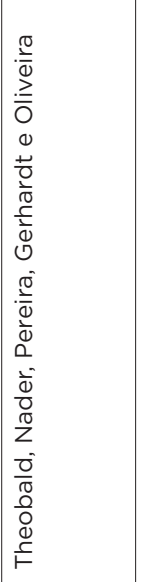 & 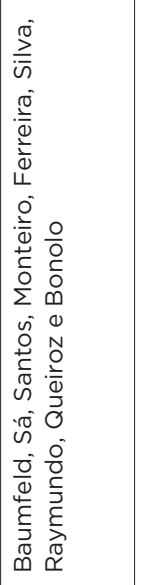 & 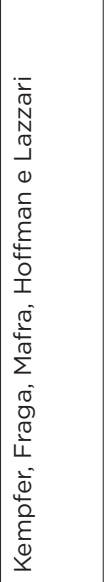 \\
\hline$\stackrel{\circ}{\frac{\tau}{4}}$ & 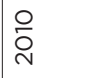 & $\overline{\bar{D}}$ & $\overline{\bar{D}}$ & $\overline{\mathrm{D}}$ & $\bar{\sim}$ & $\bar{N}$ & $\overline{\mathrm{D}}$ & $\underset{\sim}{\stackrel{N}{\sim}}$ & $\stackrel{\sim}{\stackrel{N}{N}}$ & $\underset{\sim}{\sim}$ & $\stackrel{N}{\stackrel{N}{N}}$ \\
\hline
\end{tabular}




\begin{tabular}{|c|c|c|c|c|c|c|c|c|c|c|c|c|c|}
\hline $\begin{array}{l}\text { O् } \\
\text { aे }\end{array}$ & $\begin{array}{l}\mathrm{N} \\
\stackrel{O}{v}\end{array}$ & $\begin{array}{l}\stackrel{N}{\mathrm{O}} \\
\mathrm{v}\end{array}$ & $\frac{\widetilde{O}}{\mathrm{w}}$ & $\frac{\tilde{O}}{\mathrm{w}}$ & $\begin{array}{l}\stackrel{N}{\mathrm{O}} \\
\mathrm{w}\end{array}$ & $\frac{\tilde{O}}{\omega}$ & $\stackrel{\stackrel{N}{\omega}}{\underline{\omega}}$ & $\frac{\tilde{O}}{\mathrm{~W}}$ & $\frac{\tilde{O}}{\omega}$ & $\frac{N}{N}$ & $\frac{\tilde{O}}{N}$ & $\stackrel{N}{\stackrel{N}{N}}$ & \\
\hline 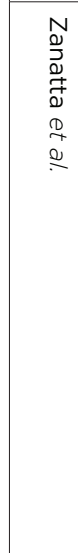 & 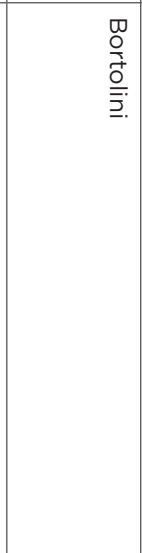 & 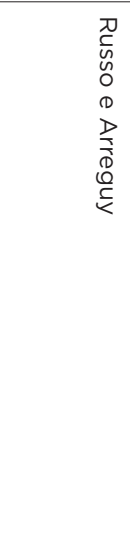 & 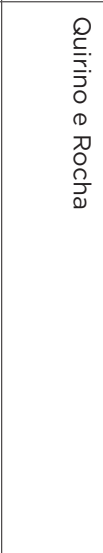 & 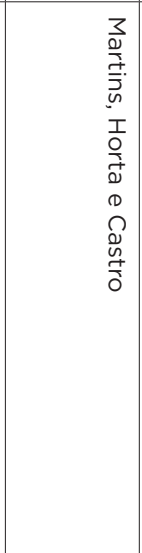 & 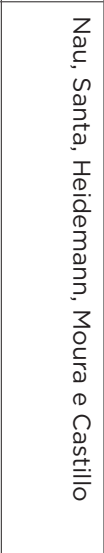 & 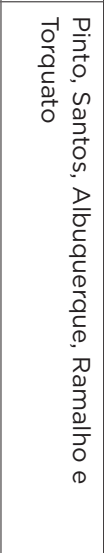 & $\begin{array}{l}z \\
3 \\
\frac{3}{7} \\
\overline{5} \\
w \\
0 \\
0 \\
n \\
0 \\
\mathbb{N} \\
0\end{array}$ & 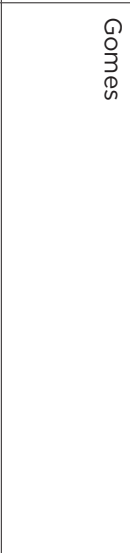 & 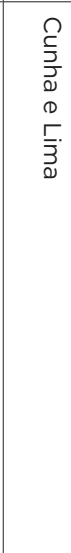 & 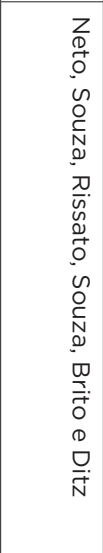 & 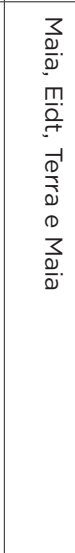 & 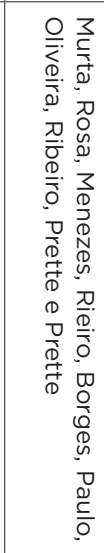 & 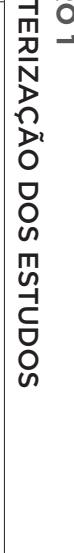 \\
\hline 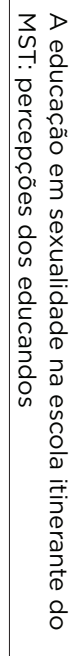 & 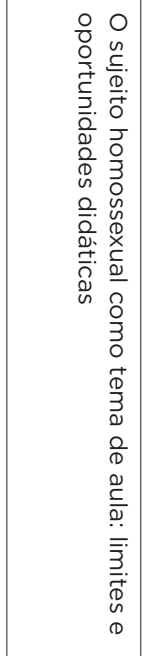 & 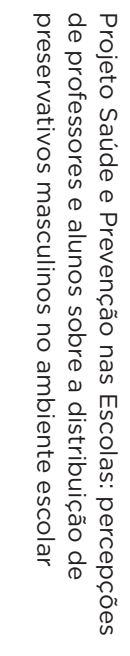 & 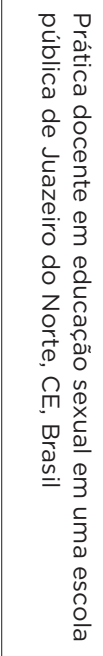 & 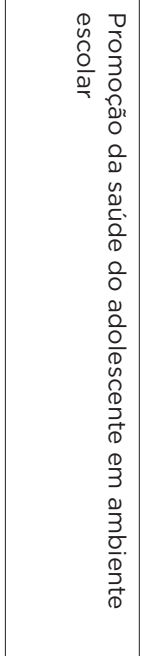 & 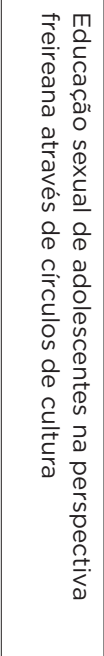 & 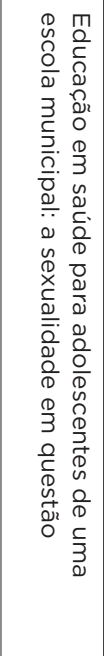 & 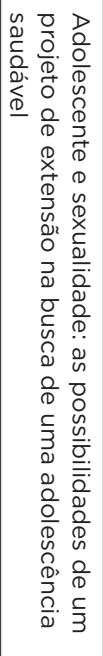 & 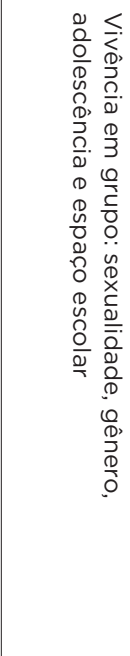 & 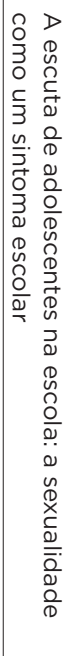 & 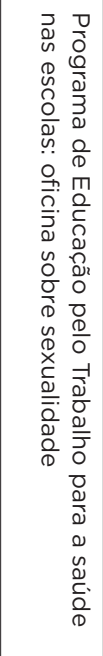 & 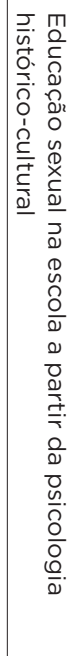 & 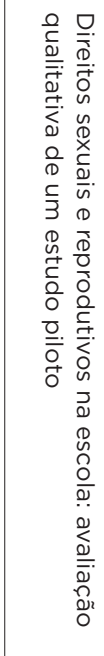 & \\
\hline 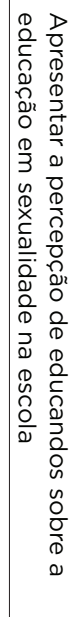 & 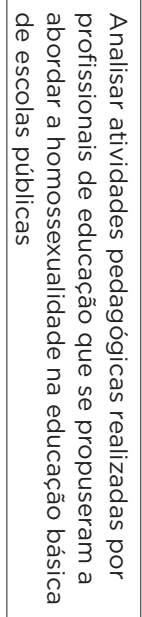 & 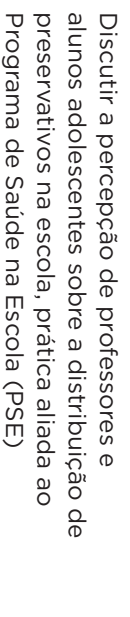 & 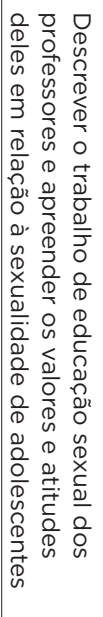 & 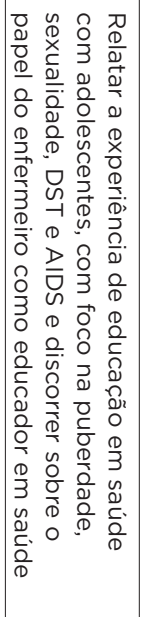 & 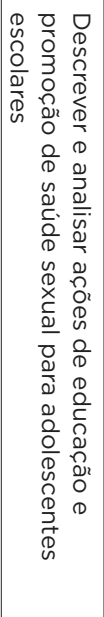 & 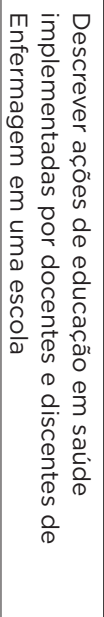 & 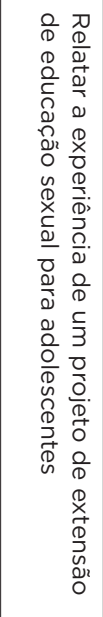 & 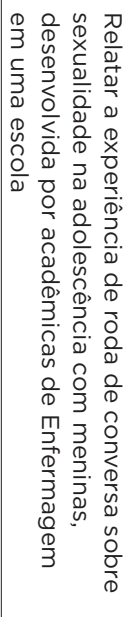 & 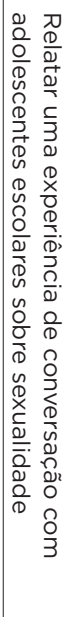 & 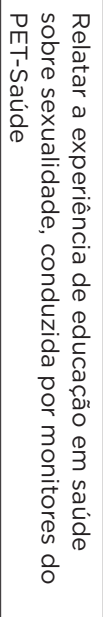 & 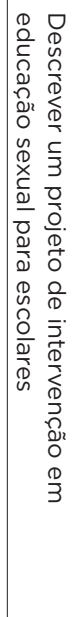 & 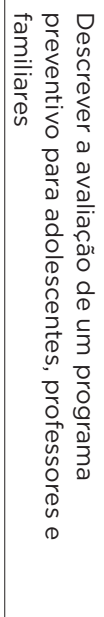 & \\
\hline 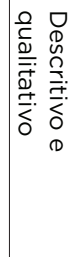 & 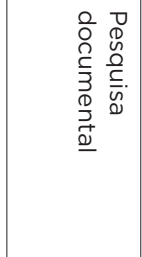 & 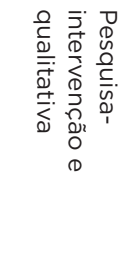 & 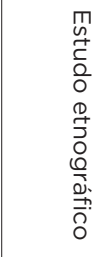 & 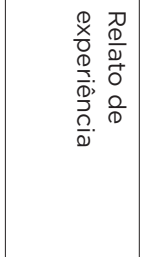 & 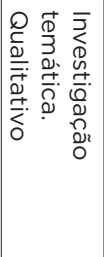 & 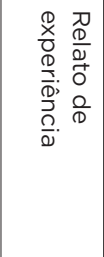 & 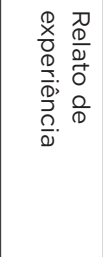 & 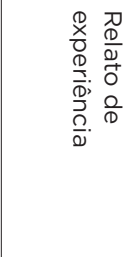 & 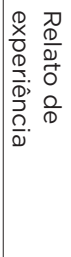 & 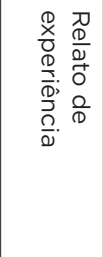 & 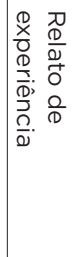 & 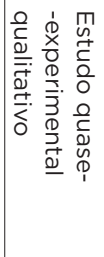 & \\
\hline
\end{tabular}




\section{CARATERÍSTICAS DA EDUCAÇÃO SEXUAL NAS ESCOLAS}

Objetivo das ações de educação sexual

Evidencia-se que a maioria dos trabalhos encontrados buscou relatar ou descrever uma intervenção de orientação/educação sexual (ALMEIDA et al., 2011; BAUMFELD et al., 2012; CUNHA; LIMA, 2013; FILHA, 2012; GOMES, 2013; KEMPFER et al., 2012; MAIA et al., 2012; MARTINS; SOUZA, 2013; MARTINS et al., 2011; MARTINS; HORTA; CASTRO, 2013; MOURA et al., 2011; NAU et al., 2013; NETO et al., 2012; PINTO et al., 2013; SILVA et al., 2011; SOUZA, 2011). O restante dos artigos buscou avaliar a orientação/educação sexual escolar a partir da percepção dos alunos e de práticas docentes (BORTOLINI, 2015; QUIRINO; ROCHA, 2013; RUSSO; ARREGUY, 2015; ZANATTA et al., 2016), avaliar a aprendizagem e percepção dos alunos a partir das intervenções educativas (FONSECA; GOMES; TEIXEIRA, 2010; MURTA et al., 2012; THEOBALD et al., 2012) e investigar as necessidades de conhecimento em sexualidade em adolescentes escolares, após a realização de intervenções educativas (BESERRA et al., 2011).

De modo geral, as atividades desenvolvidas se caracterizam por intervenções temporárias, realizadas por profissionais que não pertencem ao quadro escolar. Essas atividades atingem apenas uma parte da população escolar, concentrando $75 \%$ das ações no ensino fundamental ( $5^{\circ}$ ao $9^{\circ}$ ano), e $25 \%$ no ensino médio.

Ainda se destacam os trabalhos de Cunha e Lima (2013), Gomes (2013) e Beserra et al. (2011), que desenvolveram intervenções direcionadas apenas ao gênero feminino ou masculino. No primeiro caso, a restrição foi justificada por uma demanda escolar; já no segundo e terceiro casos, visaram a atender às necessidades específicas do grupo. Não foram identificadas atividades de educação sexual para as séries iniciais ( $1^{\circ}$ ao $4^{\circ}$ ano).

\section{Características metodológicas e pedagógicas}

No que tange às principais características metodológicas e pedagógicas utilizadas nas ações de educação sexual, percebeu-se a existência de uma diversidade de modalidades de intervenção. Dentre elas, houve preferência pela utilização de oficinas (50\%), cuja escolha se justifica por ser uma prática que permite maior interação entre os participantes e a construção coletiva do conhecimento, contando com um ou mais facilitadores como propulsores das discussões (MARTINS; HORTA; CASTRO, 2013). Outras atividades utilizadas foram a conversação com os alunos (CUNHA; LIMA, 2013; MAIA et al., 2012), leitura de livros infantis (FILHA, 2012), elaboração de peça teatral (SOUZA, 2011), dinâmicas de grupo e atividades lúdicas (BAUMFELD et al., 2012; FONSECA; GOMES; TEIXEIRA, 2010), intervenções psicoeducativas (MURTA et al., 2012), círculo de cultura (BESERRA et al., 2011; NAU et al., 2013) e grupo operativo (GOMES, 2013). 
Métodos ou teorias pedagógicas específicas foram utilizados por 85\% dos estudos como fundamentação para realização das atividades. Dentre estas destacam-se: metodologia freireana e círculos de cultura (BESERRA et al., 2011; GOMES, 2013; NAU et al., 2013; NETO et al., 2012; SILVA et al., 2011), metodologia participativa (ALMEIDA et al., 2011; BAUMFELD et al., 2012; FONSECA; GOMES; TEIXEIRA, 2010; MARTINS; SOUZA, 2013; MARTINS et al., 2011; MARTINS; HORTA; CASTRO, 2013), metodologia informativa (KEMPFER et al., 2012), psicoeducação (MURTA et al., 2012), metodologia interacionista (PINTO et al., 2013), educação pela experiência de Dewey (SOUZA, 2011) e abordagem histórico-cultural (MAIA et al., 2012; MOURA et al., 2011).

Especificamente quanto ao tipo de pesquisa realizado, destaca-se que a maioria dos estudos avaliados se caracterizou como sendo um relato de experiência de intervenções realizadas. Apenas o trabalho de Murta et al. (2012) apresentou o processo de avaliação de intervenções que incluiu adolescentes, familiares e professores. Constatou-se que o programa favoreceu a construção de fatores de proteção para a saúde sexual e reprodutiva de adolescentes, serviu como apoio social para as famílias e sensibilizou para o trabalho em equipe para os professores. Houve a sugestão de que as intervenções tivessem maior duração.

\section{Temáticas abordadas nas intervenções}

Houve predomínio de temas que respondiam à abordagem médico-informativa, relacionada estritamente à prevenção de doenças sexualmente transmissíveis e gestação (CUNHA; LIMA, 2013; KEMPFER et al., 2012; THEOBALD et al., 2012). Esses trabalhos tiveram como foco o fornecimento de informações relacionadas à biologia do sexo, características sexuais secundárias e atitudes necessárias para a manutenção da saúde. Outros estudos abordaram temas diversos, envolvendo não somente reprodução e fisiologia, mas também discussões sobre normas de gênero e identidade, preconceito, diversidade e aspectos culturais e familiares (FILHA, 2012; MAIA et al., 2012; MURTA et al., 2012).

Na eleição dos temas envolvidos nas intervenções, identificou-se também a abordagem dialógica. Nessas intervenções, considerava-se o relato dos alunos como relevante e necessário para a construção do conhecimento, permitindo que as temáticas trabalhadas emergissem da participação das turmas. Apesar disso, muitas intervenções continuaram enfatizando temas relativos à área da saúde sexual e reprodutiva e não abordaram a sexualidade como construção social e histórica, incluindo discussões sobre papéis e identidades de gênero, conteúdos propostos pelos Parâmetros Curriculares Nacionais (ALMEIDA et al., 2011; BAUMFELD et al., 2012; BESERRA et al., 2011; FONSECA; GOMES; TEIXEIRA, 2010; GOMES, 2013; MARTINS; SOUZA, 2013; MARTINS et al., 2011; 
MARTINS; HORTA; CASTRO, 2013; MOURA et al., 2011; NAU et al., 2013; NETO et al., 2012; PINTO et al., 2013; SILVA et al., 2011; SOUZA, 2011).

Paralelamente aos temas abordados nas ações avaliadas, alguns autores indicaram que temáticas relativas ao preconceito e à discriminação permeavam as discussões. Além disso, o despreparo dos docentes para lidar com os questionamentos sobre gênero e sexualidade foi apontado em alguns estudos, conforme pode ser observado no Quadro 2.

\section{QUADRO 2}

PRECONCEITO E DISCRIMINAÇÃO SEXUAL NAS ESCOLAS

\begin{tabular}{|l|l|}
\hline \multicolumn{1}{|c|}{ ESTUDO } & \multicolumn{1}{c|}{ CARACTERÍsTICAS } \\
\hline Zanatta et al. (2016) & $\begin{array}{l}\text { Evidenciou abordagem repressora dos professores em } \\
\text { relação aos questionamentos e dúvidas sobre sexualidade em } \\
\text { sala de aula. }\end{array}$ \\
\hline Bortolini (2015) & $\begin{array}{l}\text { As ações de educação sexual são realizadas apenas sob o } \\
\text { entendimento da heteronormatividade. }\end{array}$ \\
\hline Quirino e Rocha (2013) & $\begin{array}{l}\text { Perpetuação de crenças homofóbicas e heteronormativas } \\
\text { entre alunos e professores. Falta de diálogo professor-aluno } \\
\text { referente às questões sexuais. }\end{array}$ \\
\hline Russo e Arreguy (2015) & $\begin{array}{l}\text { Profissionais da escola não aprovam o trabalho da } \\
\text { sexualidade em ambiente escolar. }\end{array}$ \\
\hline
\end{tabular}

Fonte: Elaboração dos autores.

\section{PROFISSIONAIS QUE DESENVOLVEM AS AÇÕES DE EDUCAÇÃO SEXUAL NAS ESCOLAS}

No ambiente escolar, os professores de Ciências e Biologia têm sido os principais responsáveis pela educação sexual (16,6\%), enquanto, nas intervenções externas, caracterizadas por ações temporárias na escola, profissionais da Enfermagem se destacam (37,5\%). A maioria dos estudos analisados tinha seus objetivos vinculados à formação de profissionais da graduação em enfermagem, tendo caráter de pesquisa e intervenção. Assim, alguns artigos descreveram o desenvolvimento de projetos de extensão, estágios universitários ou intervenções do Programa de Educação pelo Trabalho - PET-Saúde (ALMEIDA et al., 2011; BAUMFELD et al., 2012; FONSECA; GOMES; TEIXEIRA, 2010; GOMES, 2013; KEMPFER et al., 2012; MAIA et al., 2012; MARTINS; SOUZA, 2013; MARTINS et al., 2011; MARTINS; HORTA; CASTRO, 2013; MOURA et al., 2011; MURTA et al., 2012; NAU et al., 2013; NETO et al., 2012; PINTO et al., 2013; SILVA et al., 2011; THEOBALD et al., 2012). No Quadro 3, identificam-se os profissionais responsáveis pelas ações de educação sexual nos estudos analisados. 


\begin{tabular}{|l|c|c|}
\hline \multicolumn{1}{|c|}{ PROFISSIONAIS } & N & $\%$ \\
\hline Enfermagem & 9 & 37,5 \\
\hline Professores (Biologia ou Ciências) & 4 & 16,6 \\
\hline Outras áreas da saúde (Ed. Física, Farmácia) & 4 & 16,6 \\
\hline Psicologia & 2 & 8,3 \\
\hline Medicina & 2 & 8,3 \\
\hline Não especificado (pesquisa) & 3 & 12,5 \\
\hline
\end{tabular}

Fonte: Elaboração dos autores.

\section{DISCUSSÃO}

Segundo os PCN, a orientação sexual na escola é entendida como atividade transversal, perpassando todos os níveis de ensino e disciplinas ou atividades escolares, já que se trata de uma questão inerente ao ser humano, construída coletiva e socialmente ao longo do seu desenvolvimento e moldada nas suas relações. Sendo assim, o documento orienta que a sexualidade deve ser trabalhada de duas formas: dentro da programação pedagógica, por meio de conteúdos já transversalizados nas diferentes áreas do currículo, e em extraprogramação, sempre que surgirem questões relacionadas ao tema (BRASIL, 1998; PALMA et al., 2015).

A partir do $5^{\circ}$ ano, além da transversalização, a orientação sexual deveria ser sistematizada e assumir um espaço específico, já que, a partir dessa faixa etária, há melhor compreensão sobre as questões relacionadas à sexualidade, assim como mais curiosidade e capacidade de diálogo (BRASIL, 1998). Furlani (2011b) corrobora essa visão, afirmando que a sexualidade perpassa todas as fases do desenvolvimento humano e a educação sexual escolar deve ter um caráter sistemático, contínuo e abrangente.

Contudo, nesta revisão da literatura, identificaram-se incongruências em relação a esses pressupostos, já que a maioria das ações foram classificadas como projetos pontuais que não fazem parte de uma prática escolar contínua. Esse resultado vai ao encontro de outros estudos que evidenciam carência de educação sexual nas escolas (FIGUEIRÓ, 2010; GAVA; VILELLA, 2016; GESSER; OLTRAMARI; PANISSON, 2015; NOTHAFT et al., 2014; SILVA; GUERRA, 2013).

A escola é compreendida como espaço que cumpre uma função social, responsável pela evolução intelectual, física, social e cultural dos indivíduos. A sexualidade, por sua vez, perpassa todos as fases do desenvolvimento dos alunos e dependerá fortemente das características da formação discente e dos diferentes modelos aprendidos na família e na escola através de professores e funcionários. A grande complexidade contida nas relações, incluindo diferentes percepções, padrões culturais e sociais e visões de mundo, torna essencial que a educação sexual 
seja trabalhada a partir de critérios norteadores, por profissionais qualificados, no intuito de diminuir conflitos e visões pessoais (DESSEN; POLONIA, 2007; GAVA; VILLELA, 2016). Apesar de existirem documentos oficiais que abordam questões sobre gênero e sexualidade, estudos mostram que os professores, principais responsáveis pela educação sexual na escola, não têm acessado esses documentos, nem recebido outros meios de capacitação (NARDI; QUARTIERO, 2012; GESSER; OLTRAMARI; PANISSON, 2015).

Essa questão reflete, em certa medida, os resultados encontrados nos estudos contemplados nesta revisão, em sua maioria relatos de experiência desenvolvidos principalmente por grupos de pesquisa vinculados à pós-graduação em áreas da saúde, especialmente Enfermagem, Medicina e Psicologia. Apesar de sua relevância social e científica, os resultados alcançados têm baixa expressividade no meio acadêmico, fazendo com que os dados sejam pouco ou nada discutidos nas graduações, tanto nas licenciaturas como nos cursos de bacharelado (FIGUEIRÓ, 2010). Em particular, quando o tema é a sexualidade, a falta de formação sistematizada conduz a estratégias diversas em termos pedagógicos e metodológicos, o que pode aumentar o risco de condutas repressivas, punitivas e discriminatórias (NOTHAFT et al., 2014; SILVA; GUERRA, 2013).

Acredita-se que a dificuldade em trabalhar a educação sexual está relacionada com a própria constituição histórica da sexualidade. As práticas higienistas e a repressão da liberdade de expressão sexual, alinhadas a algumas crenças religiosas, caracterizaram o início da educação sexual no Brasil, valorizando as relações heterossexuais, o patriarcado e a visão da sexualidade como um tabu (FIGUEIRÓ, 2010; LOURO, 2008). Essa cultura influencia até hoje a dificuldade de diálogo sobre sexualidade na escola, permitindo que apenas as informações sobre práticas preventivas sejam realizadas, especialmente nas séries finais do ensino fundamental e no ensino médio. Parece existir um temor, por parte dos professores, de que o diálogo sobre sexualidade nas séries iniciais fomente uma antecipação dos comportamentos sexuais, além do receio de provocar conflitos com as famílias (GAVA; VILLELA, 2016; GESSER; OLTRAMARI; PANISSON, 2015; NOTHAFT et al., 2014; SILVA; GUERRA, 2013; VILELAS-JANEIRO, 2008).

Soma-se a isso a abordagem médico-informativa que marcou o início das atividades de educação sexual na história do Brasil e segue encontrando espaço para ser trabalhada nas escolas, por se tratar de uma estratégia importante de saúde coletiva, mas também por seu caráter de controle e abstenção das práticas sexuais. Essa modalidade de intervenção ganha força ancorada na prevenção de doenças sexualmente transmissíveis, principalmente HIV/AIDS, e nos altos índices de gestação na adolescência (ALTMANN, 2001; FIGUEIRÓ, 2010; NARDI; QUARTIERO, 2012). Contudo, já foi assinalada, por autores como Dias (2010), Cedaro, 
Boas e Martins (2012) e Furlani (2011b), a ineficiência das intervenções informativas pontuais em relação aos comportamentos sexuais de risco entre adolescentes. Segundo os autores, se não houver uma melhoria conjunta dos fatores relacionados, tais como capacitação de profissionais, questionamento das estratégias didáticas e desenvolvimento de uma cultura que promova reflexão crítica ao longo da vida escolar, a informação perderá o sentido de autocuidado para esses jovens.

Nos últimos vinte anos, com as discussões referentes aos direitos humanos, mais especificamente relacionadas aos direitos sexuais e reprodutivos de adolescentes, e com a aprovação da Lei de Diretrizes e Bases da Educação Nacional (BRASIL, 1996), as abordagens pedagógicas têm ganhado espaço. Essa modalidade considera o adolescente protagonista, possuidor de autonomia para tomada de decisões e de direito de acesso aos serviços de saúde e informação (MORAES; VITALLE, 2015; TAQUETTE, 2013).

Nessa direção, desenvolver o sentimento de pertencimento e compreender os significados sociais atrelados aos papéis sexuais e às representações culturais possibilita a aproximação entre os indivíduos e faz com que as informações preventivas façam sentido para os adolescentes (FURLANI, 2011b). De acordo com os resultados encontrados nos estudos analisados, as ações de educação sexual nas escolas necessitam avançar nesse aspecto. Para que isso ocorra e os princípios preconizados nos PCN sejam incorporados ao dia a dia escolar, é necessário refletir sobre as formas metodológicas e pedagógicas das práticas desenvolvidas e investir em capacitação docente.

Os PCN não sugerem uma abordagem específica; entretanto, orientam que, a partir do $5^{\circ}$ ano do ensino fundamental, em espaço específico, os temas sejam levantados pelos adolescentes de forma participativa, cabendo ao educador a organização da atividade e a inclusão de temas relevantes que não tenham sido citados pelos alunos. Tal ação visa a proporcionar um espaço de diálogo, esclarecimento e problematização de questões que favoreçam a reflexão e ressignificação de informações, emoções e valores recebidos e vividos no decorrer da história (BRASIL, 1998).

Os PCN também atentam para a importância de trabalhar a sexualidade na escola a partir de uma visão sócio-histórica, ressignificando normas e padrões vigentes de gênero e identidade, no intuito de fomentar o respeito, a garantia dos direitos sexuais e a extinção de situações de preconceito e violência (BRASIL, 1998). A abordagem sócio-histórica da sexualidade tem sido indicada por autores como Figueiró (2010), Furlani (2011a), Goldberg (1988) e Louro (2008), que sinalizam que toda estratégia de educação sexual tem uma contribuição social, mas que apenas aquelas comprometidas com a transformação social poderão auxiliar na desconstrução de padrões de comportamento sexual excludentes. 
A educação sexual amparada no resgate histórico e cultural também sustenta a abordagem definida como emancipatória ou libertadora, que reconhece a tal estratégia como instrumento de busca de felicidade e transformação dos padrões de relacionamento sexual. Nesse entendimento, o educador não deve limitar-se ao conhecimento de informações científicas descontextualizadas da realidade em que vivem os sujeitos. Uma abordagem emancipatória valoriza tanto o aspecto informativo quanto o formativo, considerando o contexto em que vivem os sujeitos, com vistas a auxiliar a compreensão das normas sexuais como construção social, atentar para o respeito à diversidade sexual e de gênero e para o alcance dos direitos sexuais e reprodutivos, possibilitando a vivência da sexualidade com liberdade e responsabilidade (FIGUEIRÓ, 2010).

A transversalização indicada nas diretrizes nacionais implica a necessidade de o professor dominar, além dos conteúdos específicos de sua área, o conhecimento em relação às manifestações em sexualidade no ambiente escolar (JAQUES; PHILBERT; BUENO, 2012; PALMA et al., 2015). No entanto, essa habilidade pedagógica não é desenvolvida ao longo da profissionalização, uma vez que os cursos de capacitação são raros e comumente não incentivados pelas instituições (GAVA; VILLELA, 2016; GESSER; OLTRAMARI; PANISSON, 2015; NARDI; QUARTIERO, 2012). A formação continuada para esses profissionais seria fundamental, considerando a complexidade da prática que envolve fatores individuais, limites do próprio educador e diversidade das demandas que emergem por parte dos alunos, e contextuais, como a cultura institucional estigmatizante, adequação dos conteúdos e metodologia frente à escassez de recursos materiais e humanos para dar suporte ao trabalho em sala de aula, já que é comum que cada professor seja responsável por um número expressivo de alunos (GAVA; VILLELA, 2016; NARDI; QUARTIERO, 2012; MADUREIRA; BRANCO, 2015; PALMA et al., 2015). Além disso, a escola e equipe pedagógica necessitam ser entendidas como agentes de normalização dos comportamentos de ordem sexual, mesmo que a educação formal em sexualidade não ocorra. Nardi e Quartiero (2012) salientam a importância de mobilizar o cotidiano escolar, em relação à educação sexual, a fim de diluir as resistências da instituição escolar em colocar as intervenções em prática, o que tem sido evidenciado em estudos recentes (GAVA; VILELLA, 2016; JAQUES; PHILBERT; BUENO, 2012; MADUREIRA; BRANCO, 2015; SILVA; GUERRA, 2013).

Contudo, pesquisas sugerem que, dentre as principais dificuldades para a implementação das estratégias de educação sexual, estão as crenças sexistas e religiosas de pais e professores, que compreendem alguns comportamentos sexuais como desvios, o receio de represália da comunidade escolar e o desconforto para lidar com a temática (JAQUES; PHILBERT; BUENO, 2012; GAVA; VILLELA, 2016; NARDI; QUARTIERO, 2012; 
MADUREIRA; BRANCO, 2015). Nesse sentido, a discussão e expressão da sexualidade são reprimidas, sendo que tal conduta, pautada em discriminação e preconceito, é contrária aos direitos humanos e às orientações contidas nos PCN (PALMA et al., 2015).

Além disso, o retrocesso político no campo da educação sexual, que retirou da Base Nacional Comum Curricular (BNCC) os termos gênero e orientação sexual e generalizou esses temas para "dimensões da sexualidade humana” (BRASIL, 2017, p. 347), é indicativo de que ainda há muito que avançar nessa temática em termos regimentais (leis), teóricos (estudos) e pragmáticos (por meio de ações efetivas nas escolas). Segundo a Organização Mundial de Saúde, o Brasil alcança a quinta posição mundial na taxa de homicídio de mulheres - 4,8 homicídios por $100 \mathrm{mil}$ habitantes - (WAISELFISZ, 2015) e também apresenta taxas alarmantes de assassinatos de lésbicas, gays, bissexuais e travestis (LGBT). Esses dados, mesmo que subnotificados, indicam que esses crimes de ódio vêm crescendo ao longo dos anos (GRUPO GAY DA BAHIA, 2016).

A educação sexual e as discussões sobre gênero e identidade não podem ser confundidas com qualquer tipo de doutrinação moral ou ideológica, mas devem estar associadas ao desenvolvimento da cidadania. Reprimir as diferentes formas de expressão da sexualidade humana em uma sociedade não faz com que a sexualidade deixe de existir; somente a oculta. De outra forma, aceitar a diversidade sexual e de gênero não faz com que ela se propague, mas promove uma convivência respeitosa (BAILEY et al., 2016). Nessa perspectiva, a escola se apresenta como um campo fértil de situações que refletem as relações sociais que ocorrem externamente a ela, o que justifica os avanços das estratégias de educação sexual nesses locais.

A possibilidade de refletir sobre a sexualidade e suas diferentes formas de expressão pode propiciar que professores sejam agentes de mudança em seus locais de trabalho (NARDI; QUARTIERO, 2012), destacando, assim, o caráter urgente de capacitação para a área docente. Nesse sentido, a educação sexual pode ser compreendida como ferramenta essencial para o cuidado em saúde, mas, para tanto, precisa ser incluída como prática regular e sistematizada (FIGUEIRÓ, 2010; FURLANI, 2011a, 2011b; LOURO, 2008; MADUREIRA; BRANCO, 2015).

\section{CONSIDERAÇÕES FINAIS}

Ainda que não seja uma prática recente, os dados apresentados evidenciam a necessidade de avanços na área da educação sexual nas escolas brasileiras, uma vez que suas ações ainda estão pautadas em um tratamento moral e pedagógico. É importante reconhecer que algumas práticas vêm sendo desenvolvidas e que há um esforço por parte de profissionais, especialmente os da área da saúde, para abordar a temática 
no contexto escolar, mas ainda são muitas as barreiras que impedem a consolidação das práticas previstas nos PCN, as quais precisam ser reconhecidas e superadas.

Nesse sentido, é necessário refletir criticamente sobre os processos de subjetivação de crianças e adolescentes que, desde tenra idade, internalizam preconceitos que culminam em atitudes sexuais discriminatórias entre iguais e que podem se estender à vida adulta. Além disso, é fundamental investir na capacitação dos professores, já que posturas pouco construtivas e discriminatórias provocam um duplo impacto negativo no ambiente escolar: à criança e/ou adolescente que apresenta sexualidade diferente e ao grupo.

Após aproximadamente vinte anos da implementação dos PCN, nenhum trabalho encontrado apresentou ações de educação sexual que se aproximassem do preconizado, principalmente no que diz respeito à transversalização nos diversos níveis de ensino. A capacitação, tanto de professores quanto de profissionais da área da saúde, pode ser uma estratégia para atender a essa demanda, considerando uma proposta comprometida com a transformação de padrões sexuais discriminatórios e com o cultivo de uma cultura de prevenção em saúde no ambiente escolar. Nessa direção, a Psicologia Escolar se apresenta como uma possibilidade, uma vez que profissionais especializados na área estão qualificados para intervir junto aos alunos, por meio de atividades extracurriculares, junto aos pais e responsáveis, por meio de orientações, e junto aos professores, promovendo momentos de capacitação docente.

Embora o objetivo inicial deste trabalho tenha sido alcançado, sendo possível identificar as principais características e objetivos e temas das ações de educação sexual desenvolvidas no ambiente escolar, bem como os profissionais responsáveis pelas mesmas, a discussão sobre a referida temática deve permanecer em pauta tanto no campo de investigação científica, quanto entre os profissionais que atuam nas escolas. Novas pesquisas podem ser feitas, ampliando o foco de análise e comparando, por exemplo, práticas de educação sexual nacionais e internacionais, a fim de identificar as estratégias utilizadas em outros países que possam auxiliar na fundamentação de futuras políticas públicas nacionais.

\section{REFERÊNCIAS}

*ALMEIDA, Janaína Rocha de Sousa; OLIVEIRA, Nancy Costa de; MOURA, Escolástica Rejane Ferreira; SABÓIA, Vicente de Paulo Aragão, MOTA, Maria Vaudelice; PINHO, Luciane Gonçalvez Maciel. Oficinas de promoção de saúde com adolescentes: relato de experiência. Northeast Network Nursing Journal, Fortaleza, v. 12, p. 1052-1058, 2011.

ALTMANN, Helena. Orientação sexual nos Parâmetros Curriculares Nacionais. Revista Estudos Feministas, Florianópolis, v. 9, n. 2, 2001.

* Os estudos analisados nesta revisão sistemática estão diferenciados das demais referências pelo símbolo $\left(^{*}\right)$. 
BAILEY, J. Michael; VASEY, Paul L.; DIAMOND, Lisa M.; BREEDLOVE, S. Marc; VILAIN, Eric; EPPRECHT, Marc. Sexual orientation, controversy and science. Psychological Science in the Public Interest, v. 17, n. 2, p. 45-101, 2016.

*BAUMFELD, Tiago Soares; SÁ, Raphael Botelho; SANTOS, Daniela Fernanda de Almeida; MONTEIRO, Otávio Montovanelli; FERREIRA, Mariana Benzaquen; SILVA, Edith Márcia Valadares; RAYMUNDO, Mário Augusto; QUEIROZ, Andreson Melo; BONOLO, Palmira de Fátima. Autonomia do cuidado: interlocução afetivo-sexual com adolescentes no PET-Saúde. Revista Brasileira de Educação Médica, Brasília, v. 36, n. 1, p. 71-80, 2012.

*BESERRA, Eveline Pinheiro; TORRES, Cibele Almeida; PINHEIRO, Patrícia Neyva Costa; ALVES, Maria Dalva Santos; BARROSO, Maria Grasiela Teixeira. Pedagogia freireana como método de prevenção de doenças. Revista Ciência \& Saúde Coletiva, Rio de Janeiro, v. 16, n. 1, p. 1563-1570, 2011.

*BORTOLINI, Alexandre. O sujeito homossexual como tema de aula: limites e oportunidades didáticas. Cadernos Pagu, Campinas, n. 45, p. 479-501, 2015.

BRASIL. Lei n. 9.394, de 20 de dezembro de 1996. Estabelece as diretrizes e bases da educação nacional. Diário Oficial [da] República Federativa do Brasil, Brasília, DF, 23 dez. 1996. Seção 1.

BRASIL. Parâmetros curriculares nacionais: terceiro e quarto ciclos de ensino fundamental. Secretaria de Educação Fundamental, Brasília, DF, 1998. Disponível em: < http://portal.mec.gov. br/seb/arquivos/pdf/livro102.pdf>. Acesso em: out. 2017.

BRASIL. Lei n. 13.005, de 25 de junho de 2014. Aprova o Plano Nacional de Educação - PNE e dá outras providências. Diário Oficial [da] República Federativa do Brasil, Brasília, DF, 25 jun. 2014. Disponível em: <http://www.in.gov.br>. Acesso em: jan. 2018.

BRASIL. Ministério da Educação. Base nacional comum curricular: educação é a base. Brasília, DF: MEC. Disponível em: <http://basenacionalcomum.mec.gov.br/>. Acesso em: jan. 2018.

BRASIL. Resolução CNE/CP No 2, de 22 de dezembro de 2017. Institui e orienta a implantação da Base Nacional Comum Curricular, a ser respeitada obrigatoriamente ao longo das etapas e respectivas modalidades no âmbito da Educação Básica. Disponível em: <http://basenacionalcomum.mec.gov.br/wp-content/uploads/2018/04/RESOLUCAOCNE_ CP222DEDEZEMBRODE2017.pdf>. Acesso em: maio. 2018.

BRAUN, Virginia; CLARKE, Victoria. Using thematic analysis in psychology. Qualitative Research in Psychology, v. 3, n. 2, p. 77-101, 2006.

CEDARO, José Juliano; BOAS, Luana Michele da Silva Vilas; MARTINS, Renata Moreno. Adolescência e sexualidade: um estudo exploratório em uma escola de Porto Velho RO. Psicologia: Ciência e Profissão, Brasília, v. 32, n. 2, p. 320-339, 2012.

CONSELHO NACIONAL DOS DIREITOS HUMANOS - CNDH. Resolução n. 7, de 23 de agosto de 2017. Dispõe sobre posicionamento deste Conselho Nacional dos Direitos Humanos na garantia de direito e livre debate sobre gênero e sexualidade humana em âmbito escolar. Disponível em: < http://www.sdh.gov.br/>. Acesso em: jan. 2018.

*CUNHA, Cristiane de Freitas; LIMA, Nádia Laguárdia de. A escuta de adolescentes na escola: a sexualidade como um sintoma escolar. Estilos da Clínica, Rio de Janeiro, v. 18, n. 3, p. 508-517, 2013.

DESSEN, Maria Auxiliadora; POLONIA, Ana da Costa. A família e a escola como contextos de desenvolvimento humano. Paidéia, Ribeirão Preto, v. 17, n. 36, 2007.

DIAS, Fernanda Lima Aragão et al. Riscos e vulnerabilidades relacionados à sexualidade na adolescência. Revista Enfermagem UERJ, Rio de Janeiro, v. 18, n. 3, p. 456-461, 2010.

ESPADA, José P.; MORALES, Alexandra; ORGILÉS, Mireia. Riesgo sexual en adolescentes según la edad de debut sexual. Acta Colombiana de Psicología, Bogotá, v. 17, n. 1, p. 53-60, 2014.

FERREIRA, Izalci Lucas. Projeto de lei da Câmara nº 867, de 2015. Inclui, entre as diretrizes e bases da educação nacional, o “Programa Escola sem Partido”. Disponível em: < http://www.camara. gov.br/proposicoesWeb/fichadetramitacao?idProposicao=1050668>. Acesso em: jan. 2018.

FIGUEIRÓ, Mary Neide Damico. Educação sexual: retomando uma proposta, um desafio. 3. ed. Londrina: Eduel, 2010. 
*FILHA, Constantina Xavier. A menina e o menino que brincavam de ser...: representações de gênero e sexualidade em pesquisa com crianças. Revista Brasileira de Educação, Rio de Janeiro, v. 17, n. 51, p. 627-646, 2012.

*FONSECA, Adriana Dora da; GOMES, Vera Lucia de Oliveira; TEIXEIRA, Karina Correa. Percepção de adolescentes sobre uma ação educativa em orientação sexual realizada por acadêmicos(as) de enfermagem. Escola Anna Nery, Rio de Janeiro, v. 14, n. 2, p. 330-337, 2010.

FURLANI, Jimena. Educação sexual: possibilidades didáticas. In: LOURO, G. L.; FELIPE, J.; GOELLNER, S. V. (Org.). Corpo, gênero e sexualidade: um debate contemporâneo na educação. Rio de Janeiro: Vozes, 2011a. p. 66-81.

FURLANI, Jimena. Educação sexual na sala de aula: relações de gênero, orientação sexual e igualdade étnico-racial numa proposta de respeito às diferenças. Belo Horizonte: Autêntica, 2011b.

GAVA, Thais; VILLELA, Wilza Vieira. Educação em dexualidade: desafios políticos e práticos para a escola. Sexualidad, Salud y Sociedad-Revista Latinoamericana, Rio de Janeiro, n. 24, p. $157-171,2016$.

GESSER, Marivete; OLTRAMARI, Leandro Castro; PANISSON, Gelson. Docência e concepções de sexualidade na educação básica. Psicologia \& Sociedade, Belo Horizonte, v. 27, n. 3, p. 558-568, 2015.

GOLDBERG, Maria Amélia Azevedo. Educação sexual: uma proposta, um desafio. São Paulo: Aruanda, 1988.

${ }^{*}$ GOMES, Claudia de Moraes. Vivência em grupo: sexualidade, gênero, adolescência e espaço escolar. Revista de APS, Juiz de Fora, v. 16, n. 1, p. 103-111, 2013.

GONDIM, Priscilla Santos; SOUTO, Natasha Firmino; MOREIRA, Camila Brasil; CRUZ, Maria Elisabete Costa da; CAETANO, Francisca Heronildes Patrício; MONTESUMA, Francisca Gomes. Acessibilidade dos adolescentes às fontes de informações sobre saúde sexual e reprodutiva. Journal of Human Growth and Development, São Paulo, v. 25, n. 1, p. 50-53, 2015.

GONZÁLEZ, Electra A.; MONTERO, Adela V.; MARTÍNEZ, Vania M.; MENA, Pamela G.; VARAS, Marioli E. Percepciones y experiencias del início sexual desde una perspectiva de género, en adolescentes consultantes en un centro universitario de salud sexual y reproductiva. Revista Chilena de Obstetricia y Ginecología, v. 75, n. 2, p. 84-90, 2010.

GRUPO GAY DA BAHIA. Relatório 2016: assassinatos de LGBT no Brasil. 2016. Disponível em: <https://homofobiamata.files.wordpress.com/2017/01/relatc3b3rio-2016-ps.pdf>. Acesso em: jan. 2018.

INSTITUTO BRASILEIRO DE GEOGRAFIA E ESTATÍSTICA - IBGE. Pesquisa nacional da saúde do escolar. Rio de Janeiro, 2016. Disponível em: <http://biblioteca.ibge.gov.br/visualizacao/livros/ liv97870.pdf>. Acesso em: ago. 2017.

JAQUES, André Estevam; PHILBERT, Larissa Angélica da Silva; BUENO, Sonia Maria Villela. Significados sobre sexualidade humana junto aos professores do ensino fundamental. Arquivos de Ciências Saúde da UNIPAR, Umuarama, v. 16, n. 1, p. 45-50, 2012.

*KEMPFER, Silvana Silveira; FRAGA, Sandra Mara Nunes; MAFRA, Tania Julieta; HOFFMAN, Ana Cristina da Silva; LAZZARI, Daniele Delacanal. Contracepção na adolescência: uma questão de autocuidado. Revista de Pesquisa Cuidado é Fundamental Online, Rio de Janeiro, v. 4, n. 3 , p. 2702-2711, 2012.

LOURO, Guacira Lopes. Gênero e sexualidade: pedagogias contemporâneas. Pro-posições, Campinas, v. 19, n. 2, p. 17-23, 2008.

MADUREIRA, Ana Flávia do Amaral; BRANCO, Ângela Uchoa. Gênero, sexualidade e diversidade na escola a partir da perspectiva de professores/as. Temas em Psicologia, Ribeirão Preto, v. 23, n. 3, p. 577-591, 2015.

*MAIA, Ana Cláudia Bortolozzi; EIDT, Nadia Mara; TERRA, Bruna Mares; MAIA, Gabriela Lins. Educação sexual na escola a partir da psicologia histórico-cultural. Psicologia em Estudo, Maringá, v. 17, n. 1, p. 151-156, 2012. 
*MARTINS, Alessandra Sousa; HORTA, Natália Cássia; CASTRO, Maria Consolação Gomes. Promoção da saúde do adolescente em ambiente escolar. Revista de APS, Juiz de Fora, v. 16, n. 1, p.112-116, 2013.

*MARTINS, Christine Baccarat de Godoy; FERREIRA, Lilian Ortega; SANTOS, Paula Renata Miranda dos; SOBRINHO, Mara Wanderbil Lopes; WEISS, Maria Clara Vieira; SOUZA, Solange Pires Salomé. Oficina sobre sexualidade na adolescência: uma experiência da equipe saúde da família com adolescentes do ensino médio. Revista Mineira de Enfermagem, Belo Horizonte, v. 15, n. 4, p. 573-578, 2011.

*MARTINS, Christine Baccarat de Godoy; SOUZA, Solange Pires Salomé de. Adolescente e sexualidade: as possibilidades de um projeto de extensão na busca de uma adolescência saudável. Avances en Enfermería, Bogotá, v. 31, n. 1, p. 170-176, 2013.

MORAES, Silvia Piedade de; VITALLE, Maria Sylvia de Souza. Direitos sexuais e reprodutivos na adolescência: interações ONU-Brasil. Ciência \& Saúde Coletiva, Rio de Janeiro, v. 20, n. 8, p. 2523-2531, 2015.

*MOURA, Ana Flora Müller; PACHECO, Ana Paula; DIETRICH, Cauê Fantin; ZANELLA, Andréa Vieira. Possíveis contribuições da psicologia para a educação sexual em contexto escolar. Psicologia Argumento, Curitiba, v. 29, n. 67, p. 437-446, 2011.

*MURTA, Sheila Giardini, ROSA, Isabela Oliveira; MENEZES, Jordana Calil Lopes de; RIEIRO, Marcella Regina Silva; BORGES, Ohary de Souza; PAULO, Silvia Guimarães de; OLIVEIRA, Verônica de; RIBEIRO, Danilo Cruvinel; DEL PRETTE, Almir; DEL PRETTE, Zilda. Sexual and reproductive rights at school: qualitative evaluation of a pilot study. Psicologia: Teoria e Pesquisa, v. 28, n. 3, p. 335-344, 2012.

NARDI, Henrique Caetano; QUARTIERO, Eliana. Educando para a diversidade: desafiando a moral sexual e construindo estratégias de combate à discriminação no cotidiano escolar. Sexualidad, Salud y Sociedad-Revista Latinoamericana, Rio de Janeiro, n. 11, p. 59-87, 2012.

*NAU, Angélica Luciana; SANTA, Saimon Boca; HEIDEMANN, Ivonete Teresinha Buss; MOURA, Maria da Glória; CASTILLO, Laura. Educação sexual de adolescentes na perspectiva freireana através dos círculos de cultura. Revista da Rede de Enfermagem do Nordeste, Fortaleza, v. 14, n. 5, p. 886-893, 2013.

*NETO, Ariel Sousa; SOUZA, Tássia Milenna Oliveira de, RISSATO, Ulysses Pavan; SOUZA, Priscila Morais Galvão, BRITO, Paula Vieira Nunes; DYTZ, Jane Lynn Garrison. Programa de educação pelo trabalho para a saúde nas escolas: oficina sobre sexualidade. Revista Brasileira de Educação Médica, Rio de Janeiro, v. 36, n. 1, p. 86-91, 2012.

NOTHAFT, Simone Cristine dos Santos; ZANATTA, Elisangela Argenta; BRUMM, Maria Luiza Bevilaqua; GALLI, Kiciosan da Silva Bernardi; ERDTMANN, Bernadette Kreuz; BUSS, Eliana; SILVAN, Pamela Roberta Rocha. Sexualidade do adolescente no discurso de educadores: possibilidades para práticas educativas. Revista Mineira de Enfermagem, Belo Horizonte, v. 18, n. 2, p. 284-294, 2014.

OLIVEIRA, Nália de Paula; BÉRIA, Jorge Umberto; SCHERMANN, Lígia Braun. Sexualidade na adolescência: um estudo com escolares da cidade de Manaus/AM. Aletheia, v. 43, n. 44, p. 129-146, 2014.

PALMA, Yáskara Arrial; PIASON, Aline da Silva; MANSO, Almudena Garcia; STREY, Marlene Neves. Parâmetros curriculares nacionais: um estudo sobre orientação sexual, gênero e escola no Brasil. Temas em Psicologia, Ribeirão Preto, v. 23, n. 3, p. 727-738, 2015.

*PINTO, Maria Benegelania; SANTOS, Nathanielly Cristina Carvalho de Brito; ALBUQUERQUE, Adriana Montenegro de; RAMALHO, Marclineide Nóbrega de Andrade; TORQUATO, Isolda Maria Barros. Educação em saúde para adolescentes de uma escola municipal: a sexualidade em questão. Ciência, Cuidado e Saúde, Maringá, v. 12, n. 3, p. 589-594, 2013.

*QUIRINO, Glauberto da Silva; ROCHA, João Batista Teixeira da. Prática docente em educação sexual em uma escola pública de Juazeiro do Norte, CE, Brasil. Ciência \& Educação, Bauru, v. 19, n. 3, p. 677-694, 2013.

*RUSSO, Kalline; ARREGUY, Marília Etienne. Projeto “Saúde e Prevenção nas Escolas”: percepções de professores e alunos sobre a distribuição de preservativos masculinos no ambiente escolar. Physis-Revista de Saúde Coletiva, Rio de Janeiro, v. 25, n. 2, p. 501-523, 2015. 
SANTANA, Erivelton. Projeto de lei da Câmara n. 7180, de 2014. Altera o art. $3^{\circ}$ da Lei n. 9.394, de 20 de dezembro de 1996. (Inclui entre os princípios do ensino o respeito às convicções do aluno, de seus pais ou responsáveis, dando precedência aos valores de ordem familiar sobre a educação escolar nos aspectos relacionados à educação moral, sexual e religiosa. Adapta a legislação à Convenção Americana sobre Direitos Humanos (Pacto de São José da Costa Rica), de 22 de novembro de 1969, ratificada pelo Governo Brasileiro. Disponível em: <http://www. camara.gov.br/proposicoesWeb/fichadetramitacao?idProposicao=606722>. Acesso em: jan. 2018.

SFAIR, Sara Caram; BITTAR, Marisa; LOPES, Roseli Esquerdo. Educação sexual para adolescentes e jovens: mapeando proposições oficiais. Saúde e Sociedade, São Paulo, v. 24, n. 2, p. 620-632, 2015.

SILVA, Denise Quaresma; GUERRA, Oscar Ulloa. Educación Sexual: estudio comparativo entre escuelas en Brasil y en Cuba. Cadernos de Pesquisa, São Paulo, v. 43, n. 148, p. 280-301, 2013.

SILVA, George Sobrinho; LOURDES, Luciana Aparecida de; BARROSO, Karen de almeida; GUEDES, Helisamara Mota. Comportamento sexual de adolescentes escolares. Revista Mineira de Enfermagem, Belo Horizonte, v. 19, n. 1, p. 154-166, 2015.

*SILVA, Kelanne Lima da; MAIA, Carlos Colares; DIAS, Fernanda Lima Aragão; VIEIRA, Neiva Francenely Cunha; PINHEIRO, Patrícia Neyva da Costa. A educação em saúde junto aos adolescentes para a prevenção de doenças sexualmente transmissíveis. Revista Mineira de Enfermagem, Belo Horizonte, v. 15, n. 4, p. 607-611, 2011.

*SOUZA, Vânia de. Adolescentes em cena: uma proposta educativa no campo da saúde sexual e reprodutiva. Revista da Escola de Enfermagem da USP, São Paulo, v. 45, n. 2, p. 1716-1721, 2011.

TAQUETTE, Stella R. Direitos sexuais e reprodutivos na adolescência. Adolescência e Saúde, Rio de Janeiro, v. 10, n. 1, p. 72-77, 2013.

TEIXEIRA, Ana Maria Ferreira Borges; KNAUTH, Daniela Riva; FACHEL, Jandyra Maria Guimarães; LEAL, Andrea Fachel. Adolescentes e uso de preservativos: as escolhas dos jovens de três capitais brasileiras na iniciação e na última relação sexual. Cadernos de Saúde Pública, Rio de Janeiro, v. 22, n. 7, p. 1385-1396, 2006.

*THEOBALD, Vanessa Dornelles; NADER, Silvana Salgado; PEREIRA, Denise Neves; GERHARDT, Caroline Reis; FÁBERSON, João Mocelin. A universidade inserida na comunidade: conhecimentos, atitudes e comportamentos de adolescentes de uma escola pública frente a doenças sexualmente transmissíveis. Revista AMRIGS, Porto Alegre, v. 56, n. 1, p. 26-31, 2012.

VILELAS-JANEIRO, José Manuel da Silva. Educar sexualmente os adolescentes: uma finalidade da família e da escola? Revista Gaúcha de Enfermagem, Porto Alegre, v. 29, n. 3, p. 382-390, 2008.

*ZANATTA, Luiz Fabiano; MORAES, Silvia Piedade; FREITAS, Maria José dias de; BRÊTAS, José Roberto da Silva. A educação em sexualidade na escola itinerante do MST: percepções dos(as) educandos(as). Educação e Pesquisa, São Paulo, v. 42, n. 2, p. 443-458, 2016.

WAISELFISZ, Julio Jacobo. Mapa da violência 2015: homicídio de mulheres no Brasil. 1. ed. Brasília, DF: Flacso Brasil, 2015. Disponível em: <www.mapadaviolencia.org.br>. Acesso em: jan. 2018. 